УДК 050:004.738.5(571)

DOI 10.20913/2618-7515-2019-4-27-31

\title{
СИБИРСКО-ДАЛЬНЕВОСТОЧНАЯ САМОДЕЯТЕЛЬНАЯ ИНТЕРНЕТ-ПЕРИОДИКА SIBERIAN AND THE FAR EASTERN AMATEUR INTERNET PERIODICALS
}

\author{
(C) Савенко Елена Нальевна, \\ кандидат исторических наук, ведущий научный \\ сотрудник лаборатории книговедения, Госу- \\ дарственная публичная научно-техническая \\ библиотека Сибирского отделения Российской \\ академии наук, Новосибирск, Россия, \\ knigoved@spsl.nsc.ru
}

Рассмотрено влияние новых информационных технологий на периодику самиздата.

Определены преимущества интернет-СМИ. Проанализированы тенденции развития региональной любительской сетевой прессы, дана характеристика жанрово-тематического состава и целевой аудитории сибирских непрофессиональных интернет-газет и журналов.

Ключевые слова: любительская периодика, электронный аналог издания, онлайн-самиздат, сетевые издания, интернет-журналы

\author{
Savenko Elena Nalevna, \\ Candidate of Historical Sciences, Leading Researcher \\ of Laboratory of Book Study, State Public Scientific \\ Technological Library of the Siberian Branch of the \\ Russian Academy of Sciences (SPSTL SB RAS), \\ Novosibirsk, Russia, knigoved@spsl.nsc.ru
}

The influence of new information technologies on samizdat periodicals is considered. Understand the benefits of online media. The development trends of the regional amateur network press are analyzed. Characterized by the genre-thematic composition and the target audience of Siberian non-professional Internet newspapers and magazines.

Keywords: amateur periodicals, electronic analogue of the publication, online samizdat, online publications, online magazines

\section{Введение}

Бурное развитие информационных технологий оказало существенное влияние на традиционные средства массовой информации. Анализируя тенденции развития печатных СМИ в условиях интернетизации, специалисты в области журналистики и медиаведения отмечают, что важнейшим процессом преобразования прессы является конвергенция: соединение традиционной печатной и электронной версий периодического издания, слияние технологий распространения и производства [1-7]. Профессиональное журналистское сообщество по достоинству оценило возможности, предоставляемые Всемирной информационной компьютерной сетью: оперативность поступления информации к читателю, неограниченное количество потенциальных потребителей и т. д. С конца 1990-х гг. начался выход отечественных периодических изданий в интернет-пространство: появились первые электронные версии печатных газет и журналов [8]. В 2003 г., по данным базы данных Ulrich's Periodicals Directory, уже около 60\% выходивших в мире периодических изданий присутствовали в интернете [9]. Большинство отечественных периодических изданий распространяют информационный продукт в разных форматах, что позволяет им оперативно удовлетворить потребности широкой аудитории.
Появился и стал активно развиваться новый вид периодики - электронные периодические издания $[10,11]$. Как справедливо считают специалисты, возникновение сетевой периодики стало «кульминацией развития средств массовой информации и информационно-коммуникационных технологий» [12].

\section{Эволюция любительской прессы}

Новые информационные технологии стали активно использовать и создатели любительской периодики. Поскольку размещенная в Сети электронная версия печатного издания доступна широкому кругу пользователей и любой желающий может распечатать заинтересовавшие его тексты, многие «самиздатчики» перестали заботиться о тиражировании своей продукции. С конца 1990-х гг. в интернете стали появляться pdf-копии самодеятельных газет и журналов различной тематической направленности.

Первоначально наиболее распространены были электронные версии любительских литературных изданий. Однако прекращение выпуска бумажного издания вызывало автоматическое исчезновение и его интернет-«клона». В результате в настоящее время доступны онлайн-версии лишь некоторых 
сибирских самодеятельных газет и журналов, издававшихся ранее. Например, отдельные номера созданного осенью 2008 г. омского журнала нетрадиционной (авангардной) литературы «Вольный лист» представлены на веб-странице (http://reading-hall.ru/volniy-list/index.php). С электронным вариантом газеты для литературно ориентированной молодежи «Провинциал», выходившей в Абакане в 2008 г., можно ознакомиться в социальной сети «ВКонтакте» (https://vk.com/ club11709365). Содержание поэтической газеты «Взгляд», издававшейся в Комсомольске-на-Амуре в 2004-2008 гг., отражено на сайте (http://www. vzglyadik.ru).

В целях сохранения информации о своем издании и его содержимом создатели самодеятельной периодики стали создавать своеобразные онлайн-архивы, аккумулировавшие копии печатных выпусков. В 2000 г., например, в интернете появился сайт старейшего самиздатского литературного альманаха «Ликбез» (http://lik-bez.ru), на котором размещен подробный архив его номеров. Литературнохудожественный альманах «Менестрель», издающийся в Омске с 2012 г., не только имеет свой сайт в интернете (https://www.menestrelomsk. com), но и архив онлайн-версий изданий, размещенных на Евразийском журнальном портале «Мегалит» (http://www.promegalit.ru/magazines/ menestrel.html) и в социальной сети «ВКонтакте» (https://vk.com/menestrelomsk). Появились сетевые ресурсы (http://www.rusf.ru/fanzins/\#lef, https://fantlab.ru/magazines), с помощью которых можно ознакомиться с оцифрованными выпусками любительских изданий, посвященных фантастике: хабаровским журналом «Лаборатория ЛЭФ», омским «Страж - Птица» и др. Архив рок-периодики представлен на сайте http://ex-pressa.ru.

Активно используют возможности, предоставляемые интернетом, анархистские группы [13]. Электронные копии анархоизданий регулярно выкладываются на специальные анархические сайты и в социальные сети. Например, выпуски газеты иркутских анархистов «Вольная Сибирь» представлены на официальном сайте организации «Автономное действие» (https://avtonom.org/news/ vyshel-novyy-nomer-gazety-irkutskih-anarhistovvolnaya-sibir-no-16) и на онлайн-платформе ISSUU (https://issuu.com/baikalshaman/docs/vs11).

Результаты проведенного анализа показывают, что современный самиздат - это, прежде всего, субкультурное явление. Большая часть любительских периодических изданий ориентируется на специфические интересы представителей различных неформальных сообществ и транслирует их ценностные установки. Создание своеобразных «представительств» в интернете позволяет более оперативно продвигать идеи субкультурного движения и существенно расширять круг единомышленников.

Весьма популярны новейшие информационные технологии у любителей фантастики. Специалисты справедливо считают, что фэнзин оптимально приспособлен для интернета: в Сети он «приобретает информативную гибкость и... намного быстрее оповещает читателя о новинках и событиях в “фантастической” субкультуре» ${ }^{1}$. Пример конвергенции технологий выпуска фантастической периодики - альманах «Та сторона» (http://www. rusf.ru/tc/index.htm), являвшийся в 1993-1999 гг. печатным органом новосибирского неформального клуба «Лоцман». Примечательно, что члены редколлегии журнала находились в разных городах (Екатеринбург, Новосибирск, Москва) и потому сетевые технологии использовались ими не только при распространении, но и при создании новых номеров журнала. В новом тысячелетии электронную версию в интернете имеют уже многие самодеятельные печатные журналы, посвященные фантастике. В частности, фэнзин молодежного ролевого движения «Крылатый вестник», выходивший в свет в 2008-2010 гг., был доступен на сайте http://www.kvestnik.info.

Веб-сайты печатных любительских изданий создают в Сети и представители других субкультурных сообществ. Так в 2009 г. в интернете появилась электронная версия омского журнала «Патефон Сквер» (http://partyphone.narod.ru), освещавшего деятельность неформальных литературных и художественных объединений, панк- и рок-групп. Архив указанного журнала размещен на сайтах http://www.patefonskver.ru и https://www. facebook.com/patefonskver. Существуют в сетевом пространстве и веб-архивы, на которых представлены копии любительских печатных панк- и рок-изданий. Например, с содержанием дальневосточных журналов «ПостРок» (1997-1999), «Фронт» (1999-2000) и Hatross (2003-2005) можно ознакомиться на сайте https://web.archive.org/ web/20070629071409/www.hatross.ru/journal.php.

Новый культурный феномен конца XX - начала XXI в. - паранормальная субкультура. По мнению специалистов, охвативший постсоветское российское общество кризис привел к искажению картины мира и культурно-исторического процесса, к сдвигу общественного сознания в сторону оккультизма $[14,15]$. Рост интереса к паранормальным явлениям обусловил появление любительской прессы соответствующей тематики. В качестве подтверждения указанной тенденции можно упомянуть журнал мистики и черного юмора «Тюменский Рептилоид» (https://vk.com/

Навроцкая Е. Что такое фэнзины? // Журнал «Самиздат». URL: http://webcache.googleusercontent.com/search?q=cache:2sU_ htDNLd8j:samlib.ru/j/janr_1/fanzin.shtml+\&cd=2\&hl=ru\&ct=clnk\&gl=ru (дата обращения: 08.12.2016). 
tmnreptiloid), зин о черной магии «Секретное рукопожатие» (https://www.facebook.com/diyzine/ photos/a.221896777877979/381259788608343/?typ $\mathrm{e}=1$ \& theater).

Характерное явление постсоветского периода рост масштабов детско-юношеской самодеятельной прессы и качественно новый уровень ее развития [16-21]. К 2011 г. в реестре школьной прессы России по неполным данным было зарегистрировано 1399 изданий из различных уголков страны [21, с. 108]. Реальное же число самодеятельных ученических газет и журналов намного больше. Самодеятельная детская пресса настолько распространенное явление, что некоторые исследователи признают ее характерным атрибутом современной детской субкультуры. Исследование показывает, что самодеятельную прессу создают учащиеся многих школ, ученики отдельных классов, участники различных творческих объединений и пр. Примечательно, что в XXI в. любительские издания, выпускаемые подростками, выходят не только в традиционном бумажном виде. Многие детско-юношеские газеты и журналы имеют в Сети электронные копии и интернет-версии печатного издания. Например, на сайте новосибирской СОШ № 196 представлена электронная версия газеты «Школьное эхо» (http://www.s196.edu.ru/educational-space/ newspaper). Электронный аналог журнала «Баобаб» (http://baobab10.ru/), выпускавшегося в 20162018 гг. силами младших школьников новосибирской гимназии № 10, размещен в социальной сети «ВКонтакте» в группе класса.

Развитие глобальной информационной сети вызвало возникновение новой формы периодики самиздата - сетевых газет и журналов. Часть современной любительской интернетпрессы возникла в результате видоизменения выходивших ранее неформальных печатных изданий. Например, издававшийся в Барнауле с конца 1990-х гг. самодеятельный журнал «Подорожник», ориентированный на людей с ограниченными возможностями, в 2009 г. полностью «перебрался» в интернет (http://podorognik. gantor.ru). Томский музыкальный веб-журнал «Новый рок» (https://vk.com/novarock) продолжает традиции одноименного бумажного издания, печатавшегося в 2008-2010 гг. Вместе с тем многие современные любительские онлайнжурналы и газеты никаким образом не связаны с бумажными изданиями. Целевое назначение и жанрово-тематический спектр современной любительской онлайн-периодики разнообразен, что подтверждает вывод специалистов о диверсификации СМИ.

Как показывают результаты анализа, наиболее широко представлен в Сети литературный сегмент, так как интернет предоставляет бескрайний простор для самовыражения. Помимо огромного количества специальных сайтов и порталов для начинающих, малоизвестных авторов, в интернете существуют различные сетевые любительские альманахи и журналы, являющиеся полноценной альтернативой «бумажным» изданиям [22]. Любой автор при соответствии текста определенным техническим параметрам может разместить в них свое произведение. Следует отметить, что при этом удовлетворяется не только потребность в реализации творческого потенциала, но и обеспечивается оперативная связь с читателями и коллегами. Создается определенная среда общения, напоминающая литературное объединение.

Определить территориальную принадлежность сетевой любительской периодики сложно. Однако в ряде случаев место выпуска интернетиздания позволяет распознать сведения о редколлегии. Редакторами сетевого литературнохудожественного журнала «Драгоман Петровъ» (http://dragoman.narod.ru), посвященного развивающей традиции раннего русского авангарда альтернативной литературе, являлись молодые литераторы Виктор Иванов, Андрей Кузнецов, Павел Розанов, Дмитрий Умбрашко и Филипп Третьяков. Это позволяет идентифицировать журнал как новосибирское издание.

Еще одно интернет-издание, редакционный состав которого указывает на место выхода, литературный журнал «Трамвай» (http://tramline. ru) [23]. Виртуальное издание, целью которого было формирование единого художественного пространства для объединения талантливых людей, выходил в 2010-2014 гг. Создателями журнала были молодые новосибирские поэты Анатолий Каплан, Иван Полторацкий, Анатолий Квашин.

Следует отметить, что появляются и смешанные формы самодеятельной литературной периодики, когда онлайн-журналы дублируются в бумажной версии. В 2015 г. в интернете (на платформе «Сигма») появился литературно-художественный журнал «Речпорт». Наряду с электронной версией журнала по итогам года издается бумажный номер с лучшими материалами. Аналогично развивался томский журнал Vesalius (https://vk.com/ vesalius_project), выходивший с 2016 по 2018 г. Избранные материалы первых шести номеров этого электронного издания были собраны в один бумажный номер, отпечатанный тиражом 50 экз.

Современная самодеятельная онлайн-периодика это не только способ реализации творческого потенциала. Как и традиционная любительская печатная пресса, многие веб-издания являются средством коммуникации и поддержания идентичности субкультурных сообществ. В сетевом пространстве широко представлены издания, ориентированные на разнообразные интересы молодых неформалов: панков, рокеров, футбольных и хоккейных фанатов и др. Примеры 
региональной субкультурной онлайн-периодики: омский музыкальный интернет-журнал «Новый рок» (https://vk.com/novarock), онлайн-газета тюменских футбольных фанатов «Туз гейс» (http://tgexpress.narod.ru/n3.html), журнал о сибирском футболе «Таежный фанзин» (https://www. sports.ru/tribuna/blogs/siberian_fanzine).

Изучение интернет-пространства показывает, что активно осваивает современные информационные технологии молодое поколение. Интернет-периодика стала значимым источником информации и неотъемлемым элементом коммуникации молодежи [24]. Наряду с электронными аналогами самодеятельных детско-юношеских печатных изданий в сетевом пространстве появилось большое количество подростковой и молодежной онлайн-прессы сибиряков и дальневосточников. Томские школьники в возрасте от 14 до 18 лет выпускают онлайнжурнал «Штурман» (http://shturmedia.ru/tomsk). Силами учащейся молодежи Новосибирска созданы интернет-журналы «Таймикс» (https://vk.com/ club45706659) и Sib54.ru (https://vk.com/sib54ru). Юные журналисты знакомят сверстников с новостями общественной жизни города, интересной информацией о спорте, психологии, с новинками кино, музыки и литературы. Активно развивается студенческая онлайн-пресса. Студенты Новосибирского государственного университета выпускают интернет-журнал «Волна» (https://www. nsu.ru/n/media/voda/), в котором пишут о мероприятиях, личностях и событиях, происходящих внутри университета. Помимо вузовского сайта студенческое онлайн-издание представлено в социальной сети «ВКонтакте» (https://vk.com/ voda_nsu). Томские студенты запустили интернетжурнал «Ground» (https://vk.com/groundmedia). Студенты естественно-географического факультета Горно-Алтайского государственного университета публикуют в сети журнал Elife (https://vk.com/elife_egf). В список региональных студенческих интернет-изданий входят также журналы «27» (https://vk.com/magazine27, ИФиЖ, ТюмГУ), «Студенческое время» (https://vk.com/ gazeta_kuztsad, Кузнецкий техникум сервиса и дизайна) и др.

\section{Выводы}

Таким образом, можно констатировать, что новейшие информационные технологии оказали значительное влияние на неформальную прессу. Произошли существенные модификации в формах предоставления текста. Наряду с традиционными печатными самоизданными газетами и журналами появилась безбумажная любительская онлайн периодика. Анализ регионального компонента нового вида самиздата показал, что благодаря широкому спектру тематических характеристик и присущим сетевым изданиям свойствам (интерактивность, оперативность) усилилась информационно-коммуникативная роль непрофессиональной онлайн-периодики, возросла ее востребованность у различных неформальных социальных групп.

\section{Список литературы}

1. Баранова Е. А. Конвергентная журналистика. Теория и практика. М. : Юрайт, 2014. 269 с.

2. Журналистика и конвергенция: почему и как традиционные СМИ превращаются в мультимедийные / под ред. А. Г. Качкаевой. М. : Аспект пресс, 2010. 200 с.

3. Засурский Я. Н. Информационное общество в России: парадоксы интернета // Информ. о-во. 2003. Вып. 5. С. 37-41.

4. Карпенко И. И. Конвергенция в медиасреде: понятие и типы // Науч. ведомости Белгород. гос. ун-та. Сер.: Гуманитар. науки. 2013. № 13. С. 190-194.

5. Лизунова И. В. Интернет и традиционные СМИ: единство, альтернатива, конвергенция? // Средства массовой информации в контексте социокультурного развития Сибири и Дальнего Востока (90-е гг. XX - начало XXI века). Новосибирск, 2009. С. 109-128.

6. Уразова С. Л. Конвергентно-интеграционные аспекты эволюции СМИ // Вестн. ВГИК. 2010. № 5. С. 114-123.

7. Хелемендик В. С. Конвергенция как современная форма взаимодействия СМИ // Проблемы соврем. образования. 2013. № 3. С. 106-123.

8. Распопина И. А. Российская интернетжурналистика: история становления и характеристика современного состояния // Вопр. теории и практики журналистики. 2013. № 1. С. 208-214.

9. Тесля Е. В. Электронные журналы: современное состояние // Научные библиотеки: вчера, сегодня. Новосибирск, 2013. С. 153-158.

10. Градюшко А. А. Сетевая пресса в системе СМИ : учеб.-метод. комплекс. Минск : Соврем. знания, 2005. $145 \mathrm{c}$.

11. Мамедова Н. О. Типология электронных периодических изданий // Библиотечное дело - 2001. Российские библиотеки в мировом информационном пространстве : тез. докл. 6-й междунар. науч. конф. М., 2001. Ч. 2. С. 292-293.

12. Колесникова М. М. Периодические издания электронных сетей как вид СМИ : автореф. дис. ... канд. филол. наук. Ростов-на-Дону, 2002. 22 с.

13. Скращук В. В. Периодические издания анархистских организаций бывшего СССР (1987-2014 гг.) : учеб.-метод. пособие. Иркутск : Изд-во ИГУ, 2014. $118 \mathrm{c}$.

14. Александров Е. Б. «Естествознание в мире духов» // В защиту науки. М., 2015. № 16. С. 14-29.

15. Калинина Г. Н. Культурно-историческая феноменология паранауки : автореф. дис. ... д-ра филос. наук. Белгород, 2015. 45 c. 
16. Аргылов Н., Павлова Л. Школьный самиздат: актуализация «повестки дня» // Медиа. Информ. Коммуникация. 2014. № 9. URL: http://mic.org.ru/new/311shkolnyj-samizdat-aktualizatsiya-povestki-dnya (дата обращения: 05.04.2019).

17. Грудинская В. В. Современные СМИ для детей и юношества. Тенденции развития и типологические черты // Вестн. РГГУ. Сер. История. Филология. Культурология. Востоковедение. 2010. № 8. С. 163-174.

18. Ежова С. И. Самоактулизация подростков средствами периодической школьной прессы : автореф. дис. ... канд. пед. наук. Ярославль, 2005. 19 с.

19. Капустина Г. Л. Современная детская газета как тип издания: автореф. дис. ... канд. филос. наук. Воронеж, 2014. 22 с.

20. Лисеев Р. П. Молодежный журнал как субкультурный феномен : автореф. дис. ... канд. филол. наук. СПб., 2005. 17 с.
21. Лебедева С. В. Школьная самодеятельная пресса: опыт типологического анализа // Изв. Урал. гос. ун-та. Сер. 1: Проблемы образования, науки и культуры. 2011. № 2. C. 105-110.

22. Метельков А. С. Литературно-художественные журналы в интернет формате // Берковские чтения 2017. Книжная культура в контексте международных контактов : материалы IV междунар. науч. конф. (Полоцк, 24-25 мая 2017 г.). Минск, 2017. С. 219-225.

23. Полторацкий И. С. Новосибирский литературный самиздат конца XX - начала XXI века (на примере сетевого литературного журнала «Трамвай») // Вестн. НГУ, Сер.: История, филология. 2012. Т. 11, вып. 11. С. 38-47.

24. Петрова С. А. Детский сетевой журнал и его роль в современном медиаобразовании // Медиа. Информ. Коммуникация. 2015. № 12. URL: http://mic.org.ru/ new/360-detskij-setevoj-zhurnal-i-ego-rol-v-sovremennommediaobrazovanii (дата обращения: 10.03.2019). 